American Journal of Pharmaceutical Education 2021; 85 (6) Article 8468.

\title{
REVIEW
}

\section{A Systematic Review of Palliative Care Content in the Doctor of Pharmacy Curriculum}

\author{
Jennifer A. Pruskowski, PharmD, ${ }^{a, b}$ Ravi Patel, PharmD, ${ }^{b}$ Kristine Nguyen, ${ }^{b}$ CeJae Scolese, ${ }^{b}$ \\ Michele Klein-Fedyshin, MSLS, ${ }^{c}$ Gayle Brazeau, $\mathrm{PhD}^{\mathrm{d}, \mathrm{e}}$ \\ ${ }^{a}$ University of Pittsburgh, School of Medicine, Pittsburgh, Pennsylvania \\ ${ }^{\mathrm{b}}$ University of Pittsburgh, School of Pharmacy, Pittsburgh, Pennsylvania \\ ${ }^{c}$ University of Pittsburgh, Health Sciences Library System, Pittsburgh, Pennsylvania \\ ${ }^{\mathrm{d}}$ Marshall University, School of Pharmacy, Huntington, West Virginia \\ ${ }^{\mathrm{e}}$ Editor, American Journal of Pharmaceutical Education, Arlington, Virginia
}

Submitted November 9, 2020; February 5, 2021; published June 2021.

Objective. To describe the methods of teaching and evaluating palliative care experiences for pharmacy students.

Findings. A literature search retrieved 971 reports, from which 26 studies met all of study criteria. Educational interventions concerning palliative care included didactic courses, flipped classrooms, advanced pharmacy practice experiences (APPEs), workshops, and seminars. Total direct hours of education in palliative care ranged from 1-200. Seven (27\%) focused experiences were reported as required, while nine $(35 \%)$ were reported as elective. The majority $(n=14,54 \%)$ of studies measured pharmacy students' confidence, attitudes, or perceptions as the main outcome, and of those most studies reported an improvement. Five (19\%) studies reported on interprofessional experiences in palliative care conducted in the United States, and four (15\%) studies reported on similar experiences conducted outside the United States. When reported, most experiences were developed for students to complete prior to beginning their APPE year. All of the included studies used a non-randomized design.

Summary. This review suggests a palliative care experience for pharmacy students should be interprofessional, occur during the year prior to APPEs, and measure skills-based outcomes.

Keywords: palliative care, education, pharmacy, students, pharmacy

\section{INTRODUCTION}

Palliative care is a growing need within today's health care landscape. The World Health Organization (WHO) defines palliative care as "an approach that improves the quality of life of patients and their families facing the problems associated with life-threatening illness, through the prevention and relief of suffering by means of early identification and impeccable assessment and treatment of pain and other problems, physical, psychosocial and spiritual." According to the WHO's Global Atlas of Palliative Care at the End of Life, currently 20 million people worldwide would benefit from palliative care. ${ }^{1}$ This number will only increase given an aging population combined with increased chronic diseases. For example, the Administration on Aging predicts that by the year 2030 there will be

Corresponding Author: Jennifer Pruskowski, University of Pittsburgh, Kaufmann Medical Bldg., Ste. 500, 3471 Fifth Ave., Pittsburgh, PA 15213. Tel: 412-463-6217.Email: jpruskow@ pitt.edu more than 72 million Americans over 65 years of age, and the Center to Advance Palliative Care estimates that at least six million of those would benefit from palliative care. ${ }^{2,3}$

One challenge in addressing the need for palliative care is the limited number of pharmacists involved in this type of practice. ${ }^{4}$ According to the National Palliative Care Registry, in 2018 only $36(8.6 \%)$ inpatient palliative care programs reported a pharmacist as part of their team. ${ }^{5}$ One driver for this low prevalence may be the insufficiency in professional doctoral education. A 2013 survey-based study noted that schools and colleges of pharmacy devote on average only six hours of curriculum time to palliative care education. ${ }^{6}$ Considering the total hours of didactic and experiential education that a typical student pharmacist receives within a professional degree (minimum 128 credit hours), the six hours spent on palliative care accounts for less than $1 \%$ of the total curriculum. This is significantly less than what medical students receive, which is on average 12 curricular hours of material. ${ }^{7}$ In addition, to date only the Universities of Colorado, Iowa, Maryland, and 


\section{American Journal of Pharmaceutical Education 2021; 85 (6) Article 8468.}

Pittsburgh offer specialized certificate or equivalent programs for future pharmacists interested in palliative care.

Incorporating palliative care focused experiences into the Doctor of Pharmacy (PharmD) curriculum benefits student pharmacists, pharmacy schools, and the pharmacy profession overall. Even if student pharmacists do not choose to specialize in palliative care, the knowledge, skills, and perspectives gained from a palliative care-focused experience have been shown to improve students' attitudes towards end of life situations and decrease professional burnout. ${ }^{8,9}$ Palliative care experiences will also improve the school's ability to meet Accreditation Council for Pharmacy Education(ACPE) Standards 2016. ${ }^{10}$ While not explicitly stated in Standards 2016, Appendix B of the 2011 Standards acknowledges the importance of including palliative care and principles of end-of-life care in the clinical science curricular content. ${ }^{11}$ Palliative care experiences can also provide novel ways to introduce interprofessional learning to pharmacy students as the essential element in the provision of palliative care is an interprofessional team. Finally, incorporating these experiences will elevate the Doctor of Pharmacy curriculum to the curriculum of other health science programs. A 2019 commentary noted that more than 900 peer-reviewed articles describing the palliative care education of physicians are available, while only 21 involving the education of pharmacists have been published. ${ }^{12}$

Incorporating and evaluating palliative care focused education and patient care experiences will be challenging given curriculum hours are often stretched, and previous systematic reviews on this subject have not focused on pharmacy. ${ }^{13-18}$ Therefore, the purpose of this systematic review was to describe methods of teaching and evaluating palliative care experiences for pharmacy students. The goal of this systematic review was to provide guidance for schools and colleges of pharmacy looking for initial steps to incorporate palliative care education and focused experiences into their curriculums.

\section{METHODS}

This systematic review was conducted in accordance with the Institute of Medicine guidelines and reported in accordance with Preferred Reporting Items for Systematic Reviews and Meta-Analyses (PRISMA) guidelines. The protocol for this systematic review is listed on the International Prospective Register of Systematic Reviews (PROSPERO) available at https://www.crd.york.ac.uk/prospero/ display_record.php?ID=CRD42020151132.

This systematic review included peer-reviewed, published randomized controlled trials and non-randomized prospective studies. Conference abstracts, articles describing palliative care credentialing, and commentaries were excluded.
To be included in this review, studies had to focus on the palliative care education of doctoral degree or equivalent health professional pharmacy students. Studies that included postgraduate pharmacy residents, pharmacy fellows, and/or practicing pharmacists, but not PharmD students were excluded. Interprofessional experiences were also included if quantitative and/or qualitative data from pharmacy students were reported in the final analysis. Interventions involved educational experiences aimed to increase students' knowledge, skills, and/or attitudes regarding palliative care, including pain management, end of life or hospice care, deprescribing, conversations about end of life choices, and goals of care communication skills. Broad communication skills, such as shared decision making or motivational interviewing, were excluded as these are not consistently specific to palliative care. Educational delivery could include face-to-face or online methods. Comparisons included alternative teaching approaches, usual curriculum content, or historical controls. Studies without comparator arm(s) were excluded. All measures of students' knowledge, skills, and attitudes, as well as satisfaction, were applicable. Studies that only assessed interprofessional outcomes were excluded. Finally, to reduce the risk of translation bias, the studies had to be published in English. Qualitative and quantitative data were included in the final analysis.

The Cumulative Index to Nursing and Allied Health Literature (CINAHL), Education Resources Information Center (ERIC) via EBSCO, MEDLINE via PubMed, and EMBASE.com databases were searched from database inception through October 2019. Related vocabulary and keywords were combined with palliative care, education, pharmacy, and students using Boolean logic. The draft strategy was piloted and sent to the study team for review. After approval, the final strategy was translated into each database's vocabulary, command language, and syntax. Retrievals were downloaded into EndNote (Clarivate Analytics) where duplicates were removed. References cited within the included systematic reviews were also screened to identify any additional studies.

Search results were screened via DistillerSR, an online systematic review software (Evidence Partners). Two reviewers independently evaluated each title and abstract to determine eligibility for study inclusion. A full article review was conducted if any uncertainty was present regarding eligibility during the title and abstract review. In the case of disagreement between the two reviewers, the article was discussed at length with two academic pharmacists specializing in geriatrics and palliative care, and educational innovations.

The following data were collected from each included study: primary author, year and location of study, participants' demographic details, study design (number of participants, educational intervention and comparison), outcome 


\section{American Journal of Pharmaceutical Education 2021; 85 (6) Article 8468.}

measurement(s), and study results. All studies were evaluated for risk of bias using the ROBINS-I tool. ${ }^{19}$ If data extraction discrepancies or risk of bias assessments occurred, these were also resolved through discussion.

Meta-analyses were not performed because of the heterogeneity in study design, educational interventions, targeted student pharmacist training levels, outcome measures, and methodological rigor of the included studies.

\section{RESULTS}

The initial search returned 1080 abstracts. After removal of duplicates, 971 eligible records were screened. Ninetyeight full text articles and published conference abstracts were reviewed for inclusion. Several full-text articles were excluded because they did not assess a palliative care educational intervention $(n=27)$ or the study design did not meet inclusion criteria $(n=24)$. All included studies had used a non-randomized design (Figure 1, Table 1). ${ }^{20-45}$ Most were rated as having overall higher bias due to confounding and deviations from intended interventions (Table 2). ${ }^{20-45}$ No included studies were rated as having a critical risk of bias for any parameter. Twenty-six articles were included in the final qualitative analysis. ${ }^{20-45}$ The published interventions included over 6,800 health science learners and 2,700 student pharmacists. $^{20-45}$ The final studies encompassed a wide variety of experiences, including didactic courses, flipped classrooms, advanced pharmacy practice experiences (APPEs),

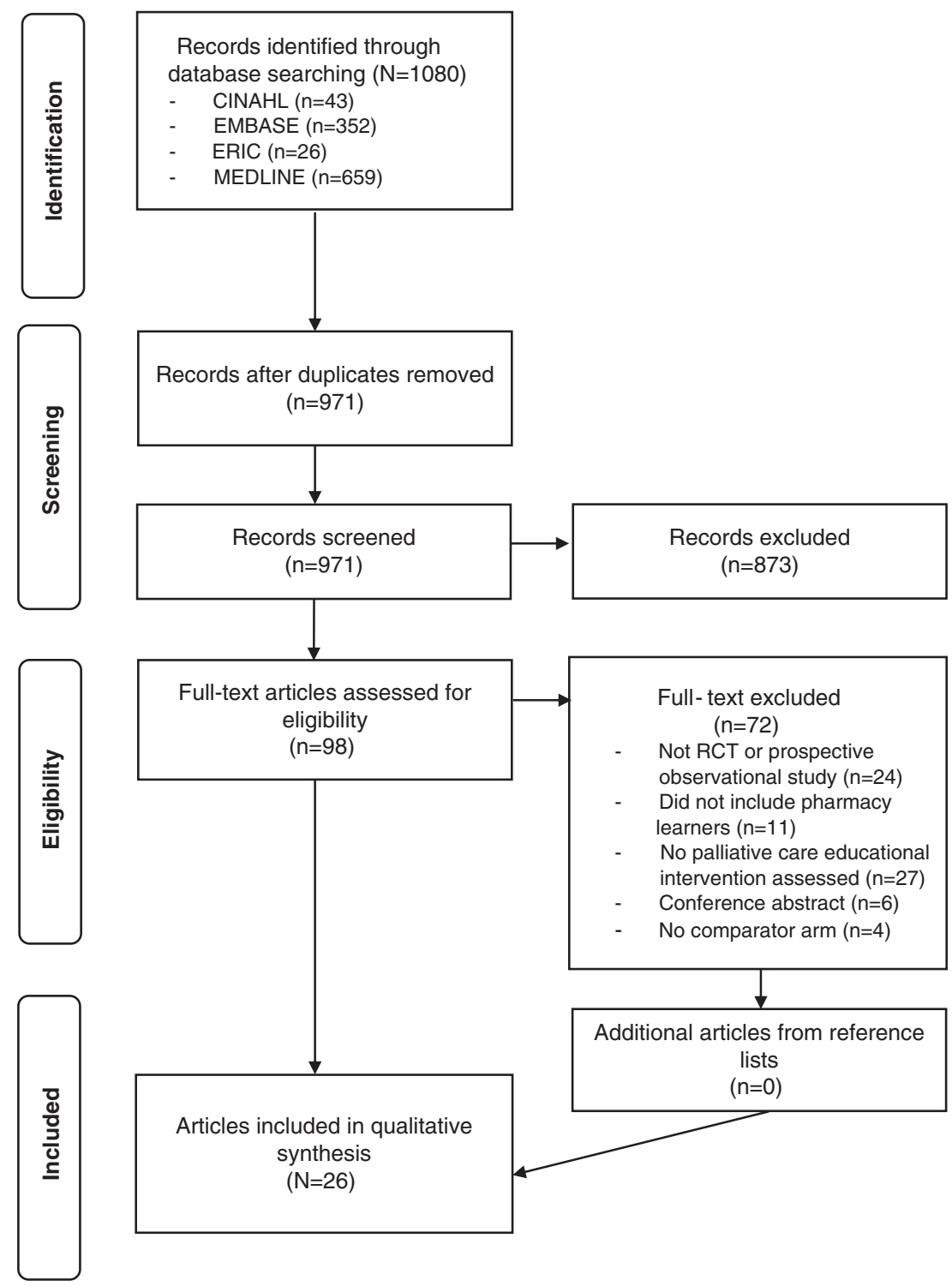

Figure 1. Flow Chart of Search Strategy and Study Selection

CINAHL $=$ Cumulative Index to Nursing and Allied Health Literature, ERIC=Education Resource Information Center (ie, EBSCOhost), RCT=randomized control trial. 
American Journal of Pharmaceutical Education 2021; 85 (6) Article 8468.

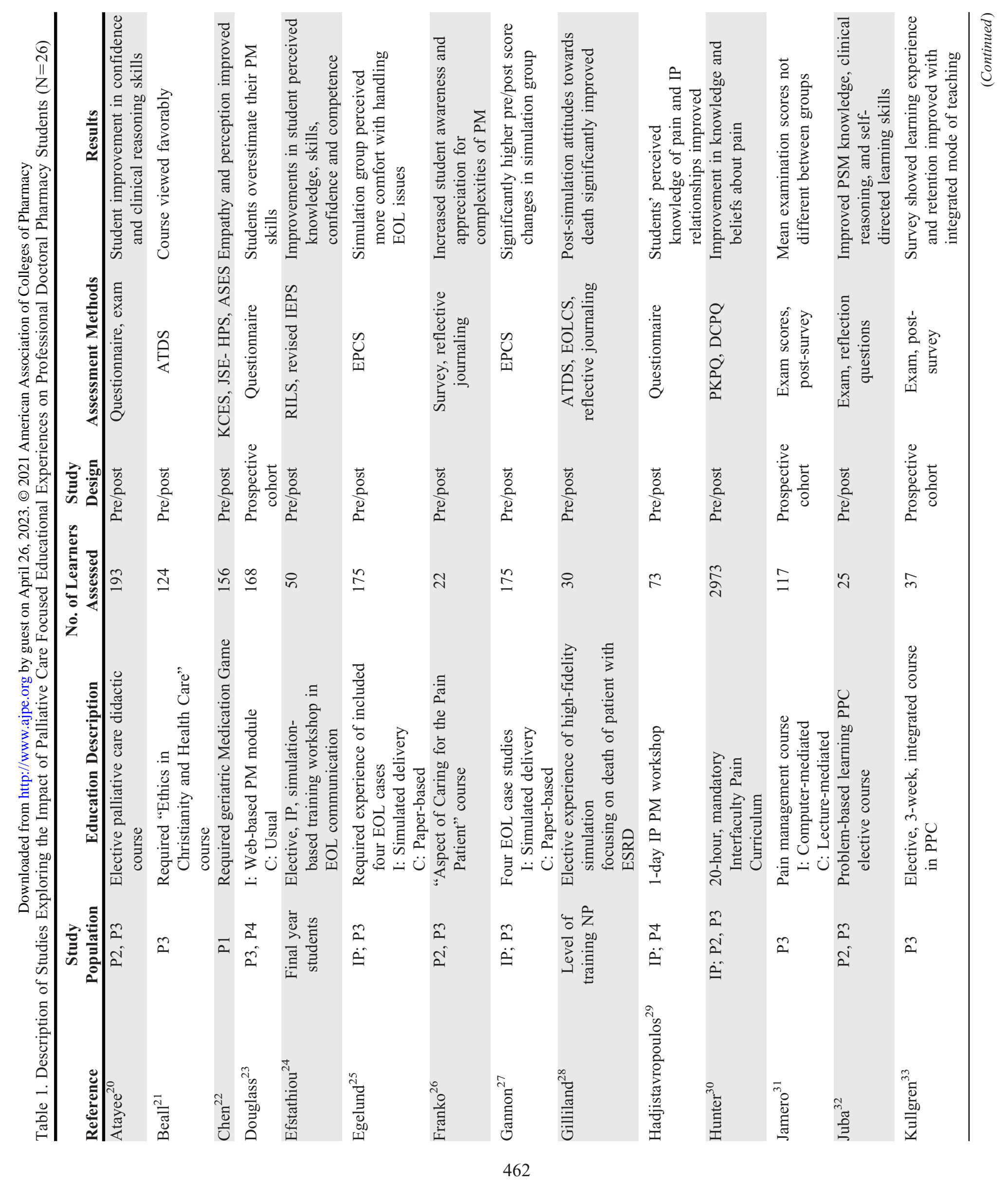


American Journal of Pharmaceutical Education 2021; 85 (6) Article 8468.

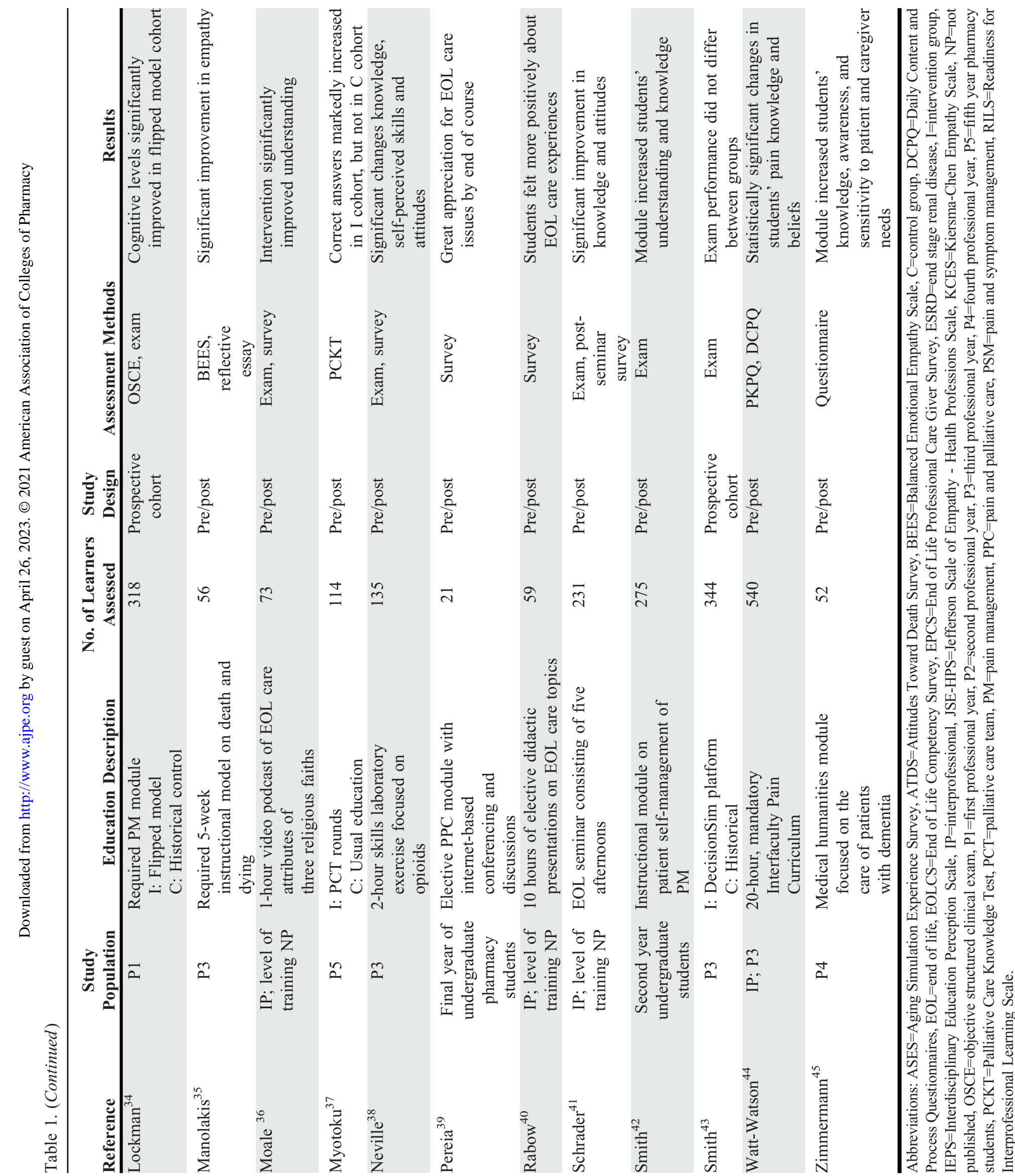




\section{American Journal of Pharmaceutical Education 2021; 85 (6) Article 8468.}

Table 2. Risk of Bias Assessment for Studies Included in a Review of Palliative Care Focused Education of Doctor of Pharmacy Students $(\mathrm{N}=26)$

Bias Category

Author, Date C PS IC DII MD OM SRR Overall

\begin{tabular}{|c|c|c|c|c|c|c|c|c|}
\hline Atayee, $2018^{20}$ & $\mathrm{~S}$ & $\mathrm{~L}$ & $\mathrm{~L}$ & $\mathrm{~L}$ & M & $\mathrm{L}$ & $\mathrm{L}$ & $\mathrm{S}$ \\
\hline Beall, $2010^{21}$ & $\mathrm{~S}$ & $\mathrm{~L}$ & $\mathrm{~L}$ & $\mathrm{~S}$ & $\mathrm{~L}$ & M & $\mathrm{L}$ & $\mathrm{S}$ \\
\hline Chen, $2015^{22}$ & $\mathrm{~L}$ & $\mathrm{~L}$ & $\mathrm{~L}$ & $\mathrm{~L}$ & $\mathrm{~L}$ & $\mathrm{~L}$ & $\mathrm{~L}$ & $\mathrm{~L}$ \\
\hline Douglass, $2015^{23}$ & $\mathrm{~S}$ & $\mathrm{~L}$ & $\mathrm{~L}$ & $\mathrm{~S}$ & $\mathrm{M}$ & M & $\mathrm{S}$ & $\mathrm{S}$ \\
\hline Efstathiou, $2014^{24}$ & $\mathrm{~S}$ & $\mathrm{~L}$ & $\mathrm{~L}$ & M & $\mathrm{L}$ & $\mathrm{L}$ & $\mathrm{L}$ & $\mathrm{S}$ \\
\hline Egelund, $2019^{25}$ & M & $\mathrm{L}$ & $\mathrm{L}$ & M & $\mathrm{L}$ & $\mathrm{L}$ & M & M \\
\hline Franko, $2018^{26}$ & $\mathrm{~S}$ & M & $\mathrm{L}$ & M & M & $\mathrm{S}$ & $\mathrm{S}$ & $\mathrm{S}$ \\
\hline Gannon, $2017^{27}$ & $\mathrm{~S}$ & $\mathrm{~L}$ & $\mathrm{~L}$ & M & $\mathrm{L}$ & $\mathrm{L}$ & $\mathrm{L}$ & $\mathrm{S}$ \\
\hline Gilliland, $2012^{28}$ & M & $\mathrm{L}$ & $\mathrm{L}$ & $\mathrm{L}$ & $\mathrm{L}$ & $\mathrm{L}$ & $\mathrm{L}$ & M \\
\hline $\begin{array}{l}\text { Hadjistavropoulos, } \\
2015^{29}\end{array}$ & M & $\mathrm{L}$ & $\mathrm{L}$ & $\mathrm{L}$ & $\mathrm{L}$ & $\mathrm{S}$ & $\mathrm{L}$ & $\mathrm{S}$ \\
\hline Hunter, $2008^{30}$ & $\mathrm{~L}$ & $\mathrm{~L}$ & $\mathrm{~L}$ & $\mathrm{~L}$ & $\mathrm{~L}$ & $\mathrm{~L}$ & $\mathrm{~L}$ & $\mathrm{~L}$ \\
\hline Jamero, $2009^{31}$ & $\mathrm{~S}$ & $\mathrm{~L}$ & $\mathrm{~L}$ & $\mathrm{~S}$ & M & $\mathrm{L}$ & $\mathrm{L}$ & $\mathrm{S}$ \\
\hline Juba, $2014^{32}$ & M & M & $\mathrm{L}$ & $\mathrm{L}$ & NI & $\mathrm{L}$ & $\mathrm{L}$ & M \\
\hline Kullgren, $2013^{33}$ & $\mathrm{~S}$ & $\mathrm{~L}$ & $\mathrm{~L}$ & $\mathrm{~S}$ & $\mathrm{~S}$ & $\mathrm{~L}$ & $\mathrm{~L}$ & $\mathrm{~S}$ \\
\hline Lockman, $2017^{34}$ & M & $\mathrm{L}$ & $\mathrm{L}$ & M & $\mathrm{L}$ & M & $\mathrm{L}$ & M \\
\hline Manolakis, $2010^{35}$ & $\mathrm{~L}$ & $\mathrm{~L}$ & $\mathrm{~L}$ & M & $\mathrm{L}$ & $\mathrm{L}$ & $\mathrm{L}$ & M \\
\hline Moale, $2019^{36}$ & NI & NI & NI & NI & NI & NI & NI & NI \\
\hline Myotoku, $2017^{37}$ & M & $\mathrm{L}$ & $\mathrm{S}$ & M & $\mathrm{L}$ & $\mathrm{L}$ & $\mathrm{L}$ & $\mathrm{S}$ \\
\hline Neville, $2014^{38}$ & $\mathrm{~S}$ & $\mathrm{~L}$ & $\mathrm{~L}$ & M & M & $\mathrm{L}$ & $\mathrm{L}$ & $\mathrm{S}$ \\
\hline Pereia, $2001^{39}$ & S & $\mathrm{L}$ & $\mathrm{L}$ & M & $\mathrm{L}$ & $\mathrm{L}$ & M & $\mathrm{S}$ \\
\hline Rabow, $2002^{40}$ & M & $\mathrm{L}$ & $\mathrm{L}$ & M & M & $\mathrm{L}$ & $\mathrm{L}$ & M \\
\hline Schrader, $2005^{41}$ & M & $\mathrm{L}$ & $\mathrm{L}$ & $\mathrm{M}$ & NI & $\mathrm{L}$ & NI & $\mathrm{M}$ \\
\hline Smith, $2013^{42}$ & M & $\mathrm{L}$ & $\mathrm{L}$ & M & $\mathrm{L}$ & $\mathrm{L}$ & $\mathrm{L}$ & M \\
\hline Smith, $2017^{43}$ & $\mathrm{~L}$ & $\mathrm{~L}$ & $\mathrm{~L}$ & $\mathrm{~L}$ & M & $\mathrm{L}$ & M & M \\
\hline $\begin{array}{l}\text { Watt-Watson, } \\
2004^{44}\end{array}$ & $\mathrm{~S}$ & $\mathrm{~L}$ & $\mathrm{~L}$ & M & $\mathrm{S}$ & $\mathrm{L}$ & M & $\mathrm{S}$ \\
\hline $\begin{array}{l}\text { Zimmermann, } \\
2013^{45}\end{array}$ & $\mathrm{~L}$ & $\mathrm{~L}$ & $\mathrm{~L}$ & $\mathrm{M}$ & $\mathrm{L}$ & $\mathrm{L}$ & $\mathrm{L}$ & $\mathrm{M}$ \\
\hline
\end{tabular}

Abbreviations: $\mathrm{C}=\mathrm{Bias}$ due to confounding, $\mathrm{DII}=\mathrm{Bias}$ due to deviations from intended interventions, $\mathrm{IC}=\mathrm{Bias}$ in classification of interventions, $\mathrm{L}=$ low risk of bias, $\mathrm{M}=$ moderate risk of bias, $\mathrm{MD}=\mathrm{Bias}$ due to missing data, $\mathrm{NI}=$ no information, $\mathrm{OM}=$ Bias in measurement of outcomes, $\mathrm{PS}=$ Bias in selection of participants into the study, $\mathrm{S}=$ serious risk of bias, $\mathrm{SRR}=$ Bias in selection of the reported results.

workshops, and seminars; total, direct hours of education ranged from $1-200 .{ }^{20-45}$ Seven (27\%) focused experiences were reported as required, while nine $(35 \%)$ were reported as elective. The majority $(n=14,54 \%)$ of studies assessed students' confidence, attitudes, or perceptions to determine study outcomes, and most studies reported an improvement. These included increased confidence, empathy, comfort with handling end of life issues, and appreciation for palliative care. ${ }^{20-28,33,35,40,42,45}$ There were five (19\%) interprofessional experiences for studies conducted within the United States, and four $(15 \%)$ for studies conducted outside the United States.*

Two studies reported introducing pain management and end of life concepts to first year pharmacy students. ${ }^{34,40}$ A 2017 study by Lockman and colleagues found that a flipped classroom model significantly improved learning outcomes as measured by an objective structured clinical examination (OSCE) and a multiple-choice examination. ${ }^{34}$ Rabow and colleagues noted that after 10 hours of presentations, students felt more positive about end-of-life care. ${ }^{40}$

When reported, most experiences were developed for pharmacy students to complete in the year prior to beginning their APPEs $(n=14,54 \%))^{* *}$ These experiences increased self-perceived and objectively measured knowledge, skills, and attitudes associated with palliative care. Beall and colleagues noted that a required Ethics in Christianity and Health Care course significantly improved students' attitudes towards death and end of life, and Manolakis and colleagues reported that completing a required, five-week instructional model on death and dying significantly improved students' empathy. ${ }^{21,35}$ A 2018 study by Franko and colleagues found that completing a two-credithour elective course increased students' awareness and appreciation for the complexities of chronic pain management. ${ }^{26}$ Atayee and colleagues found that such an experience significantly increased both students' confidence in their palliative care and clinical reasoning skills. ${ }^{20}$ Studies by Efstathiou and colleagues, Egelund and colleagues, and Gannon and colleagues reported knowledge and skills improved after students completed an interprofessional, simulation-based training. ${ }^{24,25,27}$ More specifically, Egelund and colleagues and Gannon and colleagues found significantly higher pre/ post score changes in the simulation groups compared to students in a group taught the same concepts via written content. ${ }^{25,27}$ Conversely, studies by Jamero and colleagues and Smith and colleagues found that mean examination scores were not significantly different between students who received pain management training via computermediated instruction and those who received training via lecture-mediated or written instruction. ${ }^{31,43}$

Four (15\%) articles reported on the impact of APPEs. Pereia and colleagues noted that students valued the opportunity to consolidate knowledge and gain appreciation for holistic pharmaceutical care, and Myotoku and colleagues found palliative care knowledge was significantly increased. ${ }^{37,39}$ Douglass and colleagues reported that the addition of brief, supplemental web-based experiences in

* References 24, 25, 27, 29, 30, 36, 40, 41, 44

** References 20, 21, 23, 25, 26, 30-33, 35-38, 43, 44 


\section{American Journal of Pharmaceutical Education 2021; 85 (6) Article 8468.}

addition to an APPE can also improve student confidence and competence. ${ }^{23}$

\section{DISCUSSION}

In this systematic review, we aimed to describe methods of teaching and evaluating palliative care experiences for pharmacy students with the goal of providing guidance for schools and colleges of pharmacy. We found significant heterogeneity in the study design, educational interventions, targeted student pharmacist training levels, and outcome measures among the included articles. The final studies included didactic courses, flipped classrooms, and APPEs, as well as workshops and seminars. We believe this variety provides pharmacy schools with several didactic and experiential options for incorporating palliative care experiences into their curriculum.

To our knowledge this is the first systematic review of the palliative care education of pharmacy students; however, similar results have been seen in other health science learner populations. A 2019 systematic review and metaanalysis of randomized control trials aimed at teaching palliative care to health professional students reported ${ }^{1}$ interventions were significant for improvement in knowledge and attitudes. ${ }^{19}$ In our review, the majority $(n=14$, $54 \%$ ) of studies reported students having statistically improved confidence, attitudes, and/or perceptions after completing palliative care experiences. ${ }^{20-28,33,35,40,42,45}$

While not the focus of this review, this data suggests a palliative care experience for pharmacy students should occur during the year prior to APPEs. This curriculum placement would be reasonable as by this time pharmacy students have a substantial foundation in pharmacotherapeutic knowledge and communication skills. Symptom management (eg, pain, dyspnea, nausea) is complex as it requires an understanding of medical chemistry, evidence-based medicine, and patient interview assessments skills. However, most of the included studies ( $\mathrm{n}=14,54 \%$ ) assessed students' confidence, attitudes, or perceptions as the main measurement outcome. ${ }^{20-28,33,35,40,42,45}$ This suggests palliative care experiences could be presented earlier in the curriculum when building professional attitudes is one of the major foci. Furthermore, for student pharmacists potentially interested in the field of palliative care, such experiences can support further exploration. This finding also may highlight the need for a palliative care-focused, skills-based assessment tool. Only one included study (Lockman and colleagues) focused on this important outcome. ${ }^{34}$ More studies may have evaluated this outcome if a generally accepted tool had been available.

This review was also unable to determine the minimum direct educational hours necessary for students to have an effective experience. Three $(11 \%)$ studies noted that only two hours of study can improve outcomes. ${ }^{27,38,42}$ This is also supported by a 2019 systematic review that reported a two-hour seminar accompanied by readings was sufficient to improve both pharmacy students' knowledge and attitudes. ${ }^{19}$ However, whether the impact of a shorter experience is retained could be questioned. Only one included study (Kullgren and colleagues) reported student retention of learning from a 72-hour integrated elective course on pain management and palliative care one year after graduation. ${ }^{33}$ Future studies should concentrate on the long-term effectiveness of these experiences.

There was conflicting support for computer-mediated or simulated experiences for teaching palliative care. While the studies by Egelund and colleagues and Gannon and colleagues found significantly higher pre/post score changes in the simulation groups compared to students taught the same concepts via written instruction, studies by Jamero and colleagues and Smith and colleagues noted that mean examination scores were not significantly different between groups. ${ }^{25,27,31,43}$ Simulation methods have been used extensively throughout the education of many health science disciplines as they provide a safe environment for learners to explore skills with no risks tolive patients. They also provide a spectrum of opportunities that are balanced by the required resources of educator burden and learner engagement, and an opportunity for educators to provide structured feedback. Simulations also have been shown to improve learner competence faster. Unfortunately, it does require full participation and engagement of the learner. ${ }^{46}$ Neither Jamero and colleagues nor Smith and colleagues reported whether their experiences were required or elective. ${ }^{31,43}$ If these experiences had been required, some students may have struggled with full participation and/or engagement.

Interprofessional experiences are key elements of palliative care education. Literature has shown interprofessional education leads to students having more respectful and positive attitudes as well as to self-reported improvement in ability to function within an interprofessional team and manage people with long-term conditions. ${ }^{47}$ These experiences would also prepare student pharmacists looking to specialize in palliative care. Current regulations also suggest palliative care teams should be interprofessional. Under Medicare Part A, all patients receiving hospice care have access to a physician, nurse, social worker, and chaplain. ${ }^{48}$

No included studies were rated as a critical risk of bias for any parameter; however, several articles were found to have a higher bias because of confounding. ${ }^{20-45}$ This stemmed from the susceptibility of some of the studies to the Dunning-Kruger effect because of their use of 


\section{American Journal of Pharmaceutical Education 2021; 85 (6) Article 8468.}

self-reported or self-rated student confidence and/or competence. The pharmacy students in these studies may have overestimated their ability to perform tasks. ${ }^{49}$ The literature suggests this effect can carry into realworld practice, so precautions should be considered during health science trainings. ${ }^{50}$

This review is not without several limitations. Metaanalyses were not performed because of the significant heterogeneity within the included studies. Our review included only articles published in English, thereby raising the possibility of language bias. To overcome these barriers, we presented a narrative review of the findings and searched several databases to ensure all relevant articles were included.

This review presents a variety of methods of teaching and evaluating palliative care experiences for pharmacy students. Schools and colleges of pharmacy looking for initial steps to incorporate palliative care education and focused experiences into their curriculums should consider using this review for guidance. Future studies should consider the development and validation of a skills-based palliative care measurement tool to quantify the impact of focused experiences and measure the long-term effectiveness of these experiences.

\section{CONCLUSION}

We found palliative care experiences improved students' confidence, attitudes, or perceptions however all studies included a non-randomized design. This review suggests a palliative care experience for pharmacy students should be interprofessional, occur during the year prior to APPEs and measure skills-based outcomes. To measure appropriately, there is a need for a palliative care-focused, skills-based assessment tool.

\section{REFERENCES}

1. Connor SR, Sepulveda Bernedo MC. Global Atlas of Palliative Care at the End of Life. World Health Organization, 2014. Accessed May 20, 2021.https://www.who.int/nmh/Global_Atlas_of_Palliative_Care. pdf

2. A Profile of Older Americans: 2010. Administration on Aging, United States Department of Health and Human Services. Accessed May 20, 2021. https://acl.gov/sites/default/files/

Aging\%20and\%20Disability\%20in\%20America/2010profile.pdf 3. Palliative Care Facts and Stats. Center to Advance Palliative Care, 2014. Accessed May 20, 2021. https://media.capc.org/filer_public/68/ bc/68bc93c7-14ad-4741-9830-8691729618d0/capc_press-kit.pdf 4. Cortis LJ, McKinnon RA, Anderson C. Palliative care is everyone's business, including pharmacists. Am J Pharm Educ. 2013;77(2):21.

5. National Palliative Care Registry. Center to Advance Palliative Care. Accessed May 20, 2021. https://registry.capc.org/

6. Dickinson GE. End-of-life and palliative care education in US pharmacy schools. Am J Hosp Palliat Care. 2013;30(6):532-535.
7. Head BA, Schapmire TJ, Earnshaw L, et al. Improving medical graduates' training in palliative care: advancing education and practice. Adv Med Educ Pract. 2016;(7):99-113.

8. Beall JW, Broseker AE. Pharmacy students' attitudes toward death and end-of-life care. Am J Pharm Educ. 2010;74(6):104.

9. Chuang CH, Tseng PC, Lin CY, Lin KH, et al. Burnout in the intensive care unit professionals: a systematic review. Medicine (Baltimore). 2016;95(50):e5629.

10. Accreditation Council for Pharmacy Education (ACPE) Accreditation Standard and Guidelines for the Professional Program in Pharmacy Leading to the Doctor of Pharmacy Degree. Accessed May 20, 2021. https://www.acpe-accredit.org/pdf/Standards2016FINAL.pdf 11. Accreditation Council for Pharmacy Education (ACPE) Accreditation Standard and Guidelines for the Professional Program in Pharmacy Leading to the Doctor of Pharmacy Degree. Accessed May 20, 2021. https://www.acpe-accredit.org/pdf/S2007Guidelines2.0_ ChangesIdentifiedInRed.pdf

12. Pruskowski J, Patel R, Brazeau G. The need for palliative care in pharmacy education. Am J Pharm Educ. 2019;83(5):7410.

13. Lloyd-Williams M, MacLeod RD. A systematic review of teaching and learning in palliative care within the medical undergraduate curriculum. Med Teach. 2004;26(8):683-690.

14. Bickel-Swenson D. End-of-life training in U.S. medical schools: a systematic literature review. J Palliat Med. 2007;10(1):229-235.

15. Adriaansen M, van Achterberg T. The content and effects of palliative care courses for nurses: a literature review. Int J Nurs Stud. 2008; 45(3):471-485.

16. DeCoste-Lopez J, Madhok J, Harman S. Curricular innovations for medical students in palliative and end-of-life care: a systematic review and assessment of study quality. J Palliat Med. 2015;18(4):338349.

17. Fitzpatrick D, Heah R, Patten S, Ward H. Palliative care in undergraduate medical education-how far have we come? Am J Hosp Palliat Care. 2017;34(8):762-773.

18. Donne J, Odrowaz T, Pike S, Youl B, Lo K. Teaching palliative care to health professional students: a systematic review and metaanalysis of randomized controlled trials. Am J Hosp Palliat Care. 2019; 36(11):1026-1041.

19. Sterne JA, Hernán MA, Reeves BC, et al. ROBINS-I: a tool for assessing risk of bias in non-randomised studies of interventions. $B M J$. 2016 Oct 12;355:i4919.

20. Atayee RS, Lockman K, Brock C, et al. Multicentered study evaluating pharmacy students' perception of palliative care and clinical reasoning using script concordance testing. Am J Hosp Palliat Care. 2018;35(11):1394-1401.

21. Beall JW, Broeseker AE. Pharmacy students' attitudes toward death and end-of-life care. Am J Pharm Educ. 2010;74(6):104.

22. Chen AM, Kiersma ME, Yehle KS, Plake KS. Impact of an aging simulation game on pharmacy students' empathy for older adults. Am J Pharm Educ. 2015;79(5):65.

23. Douglass MA, Chan T, Gonyeau M, Lancaster JW, Woolley AB, DiVall M. Influences of experiential year and web-based learning module on student pharmacists' confidence and competence in pain management. Curr Pharm Teach Learn. 2015;7(1):94-99.

24. Efstathiou N, Walker WM. Interprofessional, simulation-based training in end of life care communication: a pilot study. $J$ Interprof Care. 2014;28(1):68-70.

25. Egelund EF, Gannon J, Motycka C, Smith WT, Kraemer DF, Solomon KH. A simulated approach to fostering competency in end-oflife care among pharmacy students. Am J Pharm Educ. 2019;83(4): 6904. 


\section{American Journal of Pharmaceutical Education 2021; 85 (6) Article 8468.}

26. Franko TS II, Trombetta D. Impact of an innovative pain elective course on student beliefs and attitudes towards opioid medication use. Curr Pharm Teach Learn. 2018;10(9):1248-1263.

27. Gannon J, Motycka C, Egelund E, Kraemer DF, Smith WT, Solomon K. Teaching end-of-life care using interprofessional simulation. J Nurs Educ. 2017;56(4):205-210.

28. Gilliland I, Frei BL, McNeill J, Stovall J. Use of high-fidelity simulation to teach end-of-life care to pharmacy students in an interdisciplinary course. Am J Pharm Educ. 2012;76(4):66.

29. Hadjistavropoulos HD, Juckes K, Dirkse D, et al. Student evaluations of an interprofessional education experience in pain management. J Interprof Care. 2015;29(1):73-75.

30. Hunter J, Watt-Watson J, McGillion M, et al. An interfaculty pain curriculum: lessons learned from six years experience. Pain. 2008;140( 1):74-86.

31. Jamero DJ, Borghol A, Mihm L. Comparison of computermediated learning and lecture-mediated learning for teaching pain management to pharmacy students. Am J Pharm Educ. 2009;73(1):5. 32. Juba K, Ricca B. Design of a problem-based learning pain and palliative care elective course. Curr Pharm Teach Learn. 2014;6(3): 421-428.

33. Kullgren J, Radhakrishnan R, Unni E, Hanson E. An integrated course in pain management and palliative care bridging the basic sciences and pharmacy practice. Am J Pharm Educ. 2013;77(6):121. 34. Lockman K, Haines ST, McPherson ML. Improved learning outcomes after flipping a therapeutics module: results of a controlled trial. Acad Med. 2017;92(12):1786-1793.

35. Manolakis ML, Olin JL, Thornton PL, Dolder CR, Hanrahan C. A module on death and dying to develop empathy in student pharmacists. Am J Pharm Educ. 2011;75(4):71.

36. Moale AC, Rajasekhara S, Ueng W, Mhaskar R. Educational intervention enhances clinician awareness of Christian, Jewish, and Islamic teachings around end-of-life care. J Palliat Med. 2019;22(1): 62-70.

37. Myotoku M, Omotani S, Hatsuda Y, Konishi H, Hirotani Y. Enhanced understanding of the levels of palliative care in pharmacy students through participating in clinical training in hospitals. J Pharm Pract. 2017;30(3):313-317.
38. Neville MW, Bradley Clemmons A, Hunter CS. Application of opioid analgesia concepts in a third-year pharmacy student skills laboratory on three campuses. J Pain Palliat Care Pharmacother. 2014; 28(1):10-18.

39. Pereira J, Murzyn T. Integrating the "new" with the "traditional": an innovative education model. J Palliat Med. 2001;4(1):31-37.

40. Rabow MW, Petersen JJ, Schanche K. Volunteer patient advocacy: an interdisciplinary course on attending to patients at the end of life. J Palliat Med. 2002;5(5):754-755.

41. Schrader SL, Nelson ML, Eidsness L, et al. Education in end-oflife care: bridging disciplinary and institutional boundaries. SD J Med. 2005;58(9):379-388.

42. Smith L, Brown L, Bundy A, et al. A learning and teaching resource on patient self-management of chronic pain. Am J Pharm Educ. 2013;77(2):35.

43. Smith MA, Waite LH. Utilization of a virtual patient for advanced assessment of student performance in pain management. Curr Pharm Teach Learn. 2017;9(5):893-897.

44. Watt-Watson J, Hunter J, Pennefather P, et al. An integrated undergraduate pain curriculum, based on IASP curricula, for six health science faculties. Pain. 2004;110(1-2):140-148.

45. Zimmermann M. Integrating medical humanities into a pharmaceutical care seminar on dementia. Am J Pharm Educ. 2013;77(1):16. 46. Lin K, Travlos DV, Wadelin JW, Vlasses PH. Simulation and introductory pharmacy practice experiences. Am J Pharm Educ. 2011; 75(10):209.

47. Darlow B, Coleman K, McKinlay E, et al. The positive impact of interprofessional education: a controlled trial to evaluate a programme for health professional students. BMC Med Educ. 2015;15:98.

48. Medicare Hospice Benefits. Centers for Medicare \& Medicaid Services. Accessed May 20, 2021. https://www.medicare.gov/Pubs/ pdf/02154-medicare-hospice-benefits.pdf

49. Pennycook G, Ross RM, Koehler DJ, Fugelsang JA. DunningKruger effects in reasoning: theoretical implications of the failure to recognize incompetence. Psychon Bull Rev. 2017;24(6):1774-1784. 50. Sawdon M, Finn G. The 'unskilled and unaware' effect is linear in a real-world setting. J Anat. 2014;224(3):279-285. 